\title{
Placebos prompt new protocols for AIDS drug tests
}

\section{Berkeley}

THE availability in the United States of unproven AIDS drugs, while wreaking havoc on controlled drug trials, is also impelling researchers to take a hard look at the design of drug trials and the ethics of those procedures.

People with AIDS, poised as they are on a knife-edge between self-preservation and altruism, often make decisions on whether to comply with the rules of a trial based on their sense of its fairness. Concern that patients may not fully comply with the rules of trials in which they are enrolled has now stimulated a search for mutually acceptable protocols.

Placebo controls are the most highly charged issue, and possibly the most widely misunderstood. Some researchers believe that people are unaware that, once a trial drug is found to be effective for the treatment of a fatal disease, it replaces the placebo as the standard against which potential treatments are tested.

But in the absence of a proven treatment, trial designers face an ethical paradox, according to Yale medical ethicist Robert J. Levine. While testing a drug in patients is warranted only if there is reason to expect it will work, it is considered unethical to design a study in which some patients are certain to fare worse than others. The use of placebo controls becomes questionable if there is strong preliminary evidence that a drug is effective, and battles often rage over the quality and implications of this evidence.

One such controversy surrounds Protocol 019 , a trial of AZT in asymptomatic HIV-seropositive individuals being carried out at several centres. The objective is to tell whether treatment with AZT will affect the progression of those infected with HIV progressing to later stages of the disease.

The study is placebo-controlled, says principal investigator Paul Volberding, of San Francisco General Hospital, because there is no proven treatment for asymptomatic HIV infection. But Martin Delaney, of San Francisco's Project Inform, an AIDS education group, argues that, because of ample anecdotal evidence of the effectiveness of AZT, the study's placebo arm is essentially asking 1,000 patients to "fall on their swords".

In order to protect those receiving placebos, Delaney therefore argues that the clinical endpoints of the study should be more sensitively defined, and that clinical measures of progression to AIDS or AIDS-related complex (ARC) should be replaced by criteria such as the reduction of a blood parameter such as T4 cell count below a predetermined level.
Volberding defends the trial's design, claiming blood parameters are not reliable indicators of AZT's effectiveness. $\mathrm{He}$ notes that Protocol 019 may be the last placebo-controlled trial for AIDS drugs, if it proves AZT to be effective at all stages of HIV infection.

The opposition to placebo controls has driven some researchers to "telescope" drug trials by including a placebo arm in phase I safety studies, so that any early signs of a drug's efficacy can be balanced against the effects of a control. San Francisco AIDS researcher Donald Abrams is conducting such a trial of lentinin, a potential booster of the immune system extracted from shitake mushrooms. If the drug shows promise, then at least some placebo-controlled data will exist, says Abrams, in case there is resistance to a later protocol using placebo.

Mistrust of the design of trials can stifle a patient's altruistic inclinations and spur him to exploit trials in which he is enrolled for personal ends, says New York patientadvocate Tom Hannan. He tells of particitheir use of other drugs, or had their pills analysed at independent laboratories and left the study if they had been assigned to the placebo group. Volberding believes that stories such as these have been exaggerated.

The spectre of non-compliance casts a shadow of doubt on nearly all AIDS drug trials so far. The Food and Drug Administration's (FDA's) recent relaxation of pants in early AZT trials who concealed

restrictions on the import of unapproved drugs has made controlled testing of dextran sulfate impossible in the United States, according to Donald Abrams, who found that subjects in his phase-I toxicity trial were supplementing their doses with drug obtained elsewhere.

Some believe compliance can be improved through community-based trials, in which participants are supervised by their primary-care physician. Patients are more likely to follow the rules if a trusted personal physician has helped to design them, says Tom Hannan, who heads New York City's Community Research Initiative, one of several consortia using this approach.

But some researchers question whether the physicians have the experience necessary to execute sound and unbiased trials. Jack Killen, deputy director of the AIDS programme at the National Institute of Allergy and Infectious Diseases (NIAID) said the institute plans to fund more community-based trials, but not at the cost of scientific soundness.

Perhaps the most obvious, but also most problematic, way to deal with self-medicating patients is simply to monitor their medication and clinical progress. Long advocated by AIDS patients, this idea is taking hold in the research community.

While NIAID has shown interest in these monitoring studies, Killen says they would be most useful in eliminating drugs that show little promise. But what if a drug were to show promise, and the supporting evidence, while not rigorous enough to pass FDA approval, complicated the ethics of setting up a controlled trial? Says Killen: "I don't know the answer to that question."

Marcia Barinaga

\section{Medvedev promoted in Soviet shake-up}

\section{London}

VADIM Medvedev, a former head of the Science and Education Department of the Central Committee of the Communist Party of the Soviet Union, was last week elected to full membership of the Politburo, the supreme decision-making body of the Soviet Union.

He has, moreover, been appointed chairman of the newly created "Commission for Ideological affairs", thus effectively replacing as chief party ideologue the traditionalist Egor Ligachev, who for three years has been Mr Mikhail Gorbachev's main rival for the leadership. Now Gorbachev holds the dual position of President and General Secretary of the Party and Ligachev has been put in overall charge of Soviet agriculture, a position from which it is virtually impossible to succeed.

Medvedev, who is 59 years old, is very much a Gorbachev man. An economist by training, he held a succession of academic posts, rising to be Rector of the Party
Academy of Social Sciences (1978-83) and then head of the Central Committee's Science and Education Department. But these, and other posts (such as the deputy chairmanship of the Propaganda Department of the Central Committee) which he held simultaneously with his academic appointments, left him at best on the periphery of political life. Under Gorbachev, however, he was moved to the important "career" post of Central Committee secretary in charge of liaison with ruling communist parties.

Having thus been the party specialist on science and education during the final "years of stagnation" and being himself a corresponding member of the Soviet Academy of Sciences, Medvedev is undoubtedly well briefed on the hard core of "conservatism" within the academy. Any pronouncement he may make in the future on the need to reform the scientific establishment will come, therefore, from a position of strength. Vera Rich 